\title{
Using experiments to construct mathematical models for machinability characteristics of a heat resistant aluminum alloy
}

\author{
B. F. Usmanov, S. V. Starovoitov", S. K. Khadiullin and Z. R. Valishina
}

Dept. of Mechatronic Machining Systems, Ufa State Aviation Technical University, Ufa, 450000, Russia

Received 1 September 2014; Accepted 20 September 2014

\begin{abstract}
The aluminum alloy machinability was reviewed. The influence cutting mode elements on surface quality was
\end{abstract} researched. The model of influence cutting mode elements on the machined surface roughness was obtained.

Keywords: mathematical model, aluminum, cutting mode, roughness.

\section{Introduction}

It is necessary to assess the machinability, as it is one of properties of workpiece materials which determine the possibility of achieving the required technical specifications. Machinability relates to the quality of the machined surface; tool life; cutting force; permissible machining speed ; chip type; removal chip from the cutting zone conditions; etc. Roughing besides getting the best possible values of the cutting force and conditions for transfer of chips away from the cutting area. It also defines productivity as well as the machined surface roughness and the depth of the workhardened layer; degree of hardening; magnitude and sign of the residual stresses in this layer. The most reliable method of assessing the workability of a material is through experiments. - its determination by practical consideration across complex of parameters specified. Productivity and cost of processing depends mainly on the permissible cutting speed, so for cutting the main indicator of machinability is the permissible cutting speed. Getting GTE parts with the required surface quality and dimensional accuracy is a complex task. These issues have been described in a number of papers [1, 2, 3] High precision shaping details for aluminum alloys are achieved with certain parameters of machining.

\section{Surface roughness}

The roughness of a machined surface is largely associated with the formation of chips. The build-up mechanism of the chips is due to large pressure from the chip on the tool and the high temperature of plastically deformed material, as well as the asperities on the front surface of the chisel. The lower layer chip is moving away slowly producing a thin retarding layer and metal shavings are moving over this layer while overcoming internal friction. Under certain conditions this retarding layer may increase to form a new body which is firmly attached to the front surface of the

\footnotetext{
* E-mail address: sv_starov@mail.ru

ISSN: 1791-2377 @ 2014 Kavala Institute of Technology. All rights reserved.
}

cutting tool. This build-up value depends on the ratio of the frictional forces generated between the chip and the tool rake surface and the internal bond strength (shear strength) of the machined material. The greater the difference between the frictional force and the second, the larger the build-up.

Under certain conditions, the friction force affect the temperatures developed within the chip, or the cutting temperature, the value of which is directly dependent on the cutting speed. Therefore, the main cause of changes in the values of build-up to the change of cutting speed is the cutting temperature. From its magnitude it is depended the coefficient of friction of the chip front surface of the tool. At low speeds, when the temperature in the cutting area is low, the friction coefficient is relatively low, then there is no or small build-up [4].

As cutting speed increases the temperature increases as well, thus increasing the friction coefficient of the chip front surface of the tool, up until a maximum. At this point, the build-up reaches its maximum. Further increase in the velocity and temperature causes softening of the metal, reducing the coefficient of friction and the size of the buildup.

Since the cut chip slips not along the top of the tool, while at the front surface is the build-up, the actual rake angle increases, which helps to alleviate the cutting process. Due to the high hardness of the build-up, performing the functions of the cutting blade protects in part the front and back faces of the tool wear. This in turn reduces the wear of the tool, and increases its durability.

At the same time the presence of the build-up increases the roughness of the machined surface. Even YG Usachyov in 1915 found that the build-up is the cause of the irregularities on the machined surface of the workpiece even in a free cutting.

The process of irregularities forming on the surface can be treated by removing chips is as follows. The build-up with a very high hardness serves as a cutting blade. It enlarges the cutter, which is the cause of some increase in the thickness of the cut compared to the nominal value. At some point, the protruding portion buildup is so large that it 
B. F. Usmanov, S. V. Starovoitov, S. K. Khadiullin and Z. R. Valishina /

Journal of Engineering Science and Technology Review 7 (5) (2014) 51 - 54

is cut off, separated from the main part of the build-up. Part of it goes with the chips, and some remains embedded in the treated surface. This particle buildup is increasing edge roughness. Partial elimination of the buildup leads to an instantaneous decrease in the slice thickness. In the future build-up it increases in size again and the cutting thickness gradually increases until there is a protruding part forming the next edge roughness. This process is repeated periodically, which makes the entire treated surface dotted with irregularities.

\section{Aluminum alloys machinability}

Aluminum alloys have a lower hardness, lower tensile strength and higher thermal conductivity than steel. These enable to significantly increase the cutting mode. Wrought aluminum alloys are produced by rolling, molding, blanking, forging and etc. Hardenable by heat treatment aluminum alloys, duralumins can be easily machined at hardened and aged conditions, but they are not easy to machine annealed. Aluminum alloy D16 GOST 4784-97 is used for the manufacture of aviation body covers, formers and even GTE compressor blades.

It is difficult to find the optimum cutting mode for aluminum alloys because of the complex interrelationship of a number of factors. High viscosity of aluminum alloys makes metal stickto the tool face. This obstructs chip removal and probably causes rubbing marks at the machined surface [5]. The cutting forces for aluminum alloys machining is 2-4 times less than steels But aluminum alloys cause tool build-up. This process is very active as aluminum bonds well to tool materials. The maximal value and disappearance of the build-up for aluminum alloys occurs at higher cutting speeds than for steels.

It is necessary to take into account certain issues in order to eliminate build-up and to improve the machined surface roughness. When machining aluminum alloys one needs coolant for the best surface roughness. The influence of the external conditions and the lubricant and coolant fluid on the tool-blank contact is described in [6]. In general high speed machining is preferable and does not affect tool life. It is recommended to machine aluminum alloys at $\mathrm{CNC}$ machining centers because of high feed rate per minute. Tool life is reduced as surface quality worsens. In this case tool wear does not determine tool life.

The profilometer MarSurf PS1 was used to measure the machined surface roughness. The measurement was performed in accordance with GOST 2789-73. MarSurf PS1 uses a diamond pyramid $2 \mu \mathrm{m}$ tip and a measuring force 0,7 $\mathrm{mN}$.

\section{Using experimental design to optimize the cutting process.}

An experimental design allows to include both technology parameters and physic-mechanical material properties in models. It is necessary to perform a lot of experiments to identify parameters, if the depth of cut, feed rate and cutting speed change. There are two aims in the cutting processes research with an experimental design method. The first aim is to find the maximum value of the function. The second goal is to define the type of dependence for the specified range of variable parameters, which is usually studied in cutting processes research. It is necessary to find a function, which defines the relationship between the output optimization parameter and the input process parameters, so as to formulate a mathematic model of the process [5].

The cutting process is considered as a controlled system, with the cutting mode and other parameters being factors which have an effect on this. The application of experimental design allows to effectively evaluate the output parameter, reducing the amount of experiments while still being accurate. Thus, it allows solving difficult technology problems with a minimum cost usig software. By the procedure described in [7] experimental design was performed. Levels and varying intervals for variable factors of aluminum alloy D16 machinability research are presented at Table 1.

$\underline{\text { Table 1. Levels and intervals for variables }}$

\begin{tabular}{|c|c|c|c|c|}
\hline \multirow[t]{2}{*}{ Input variables } & \multirow[t]{2}{*}{ Factor } & \multicolumn{3}{|c|}{ Varying levels } \\
\hline & & Low -1 & Base 0 & $\mathrm{Up}+1$ \\
\hline Cutting speed $\mathbf{v}, \mathrm{m} / \mathrm{min}$ & $\mathbf{X}_{1}$ & 100 & 300 & 500 \\
\hline Feed rate $\mathbf{S}, \mathrm{mm} / \mathrm{rev}$ & $\mathbf{X}_{2}$ & 0,05 & 0,15 & 0,25 \\
\hline Depth of cut $\mathbf{t}, \mathrm{mm}$ & $\mathbf{X}_{3}$ & 0,1 & 0,5 & 2 \\
\hline
\end{tabular}

As a result, a mathematical model of the influence of cutting mode elements on the surface roughness was defined. Eq. 1 estimates surface roughness for the aluminum alloy D16 turning by Ti-N coated tool made from hard alloy T15K6 GOST 3882-74.

$$
\begin{aligned}
& \lg (R a)=0,052-0,001 v+0,041 s-0,036 t+0,062 v s+ \\
& 0,016 v t+0,023 s t+0,016 v^{2}+0,078 s^{2}+0,023 t^{2}
\end{aligned}
$$

Eq. 2 evaluates surface roughness for the aluminum alloy D16 turning by the same tool without coating.

$$
\begin{gathered}
\lg (R a)=-0,008-0,031 v+0,014 s-0,001 t+ \\
+0,005 v s+0,034 v t+0,028 s t+ \\
+0,021 s^{2}-0,021 t^{2}
\end{gathered} .
$$

Calculating equations 1 and 2 allows to obtain relationships between the machined surface roughness and cutting speed, feed rate, depth of cut. Machined surface roughness decreases with cutting speed increasing. The depth of cut being a geometric parameter does not affect the machined surface profile and roughness height. It affects machined surface roughness through cutting temperature, build-up conditions, shear layer deformation, the rigidness of the machine-fixture-tool-workpiece system and the changing conditions of chip removal. Thus, the machined surface roughness does not change significantly with the depth of cut.

The feed rate is the important parameter of cutting mode, which affects the cutting process productivity. The feed rate increase is limited by surface roughness during finishing. The width of the tool chip interface and normal stress at the rake face increase, but the chip ratio and tangential strain at the rake face decrease with increasing feed rate at the constant optimal cutting temperature [5]. Roughness height increases with chip ratio decreasing, because the chip section changes both thickness and width. Increased thickness chip continuously shears the top of ridges, which were formed at the machined surface and thus decreasing the roughness height. Thus, the greater chip ratio provides a better finished surface roughness. This is the explanation as to why machined surface roughness increases with feed rate. 


\section{Chip temperature measurement}

Chip temperature measurements were performed with an IR camera SDS HOTFIND V/L Series. Cutting mode was feed rate $S=0,15 \mathrm{~mm} / \mathrm{rev}$, depth of cut $t=0,5 \mathrm{~mm}$ in the speed range $v=50 \div 450 \mathrm{~m} / \mathrm{min}$ increments $50 \mathrm{~m} / \mathrm{min}$. The IR camera was installed on the stockhead of lathe $16 \mathrm{~K} 20$ and was focused at the tool tip (see Fig. 1). Video from the IR camera was recorded on the PC during the cutting pass in real time. One of screenshots from the experiment is shown in Fig. 2. The maximum chip temperature at steady state machining for each cutting speed was defined by the recorded thermal spectrums. Chip temperature graphs on cutting speed in cases of machining with a coated tool and with a without coating are shown in Fig. 3.

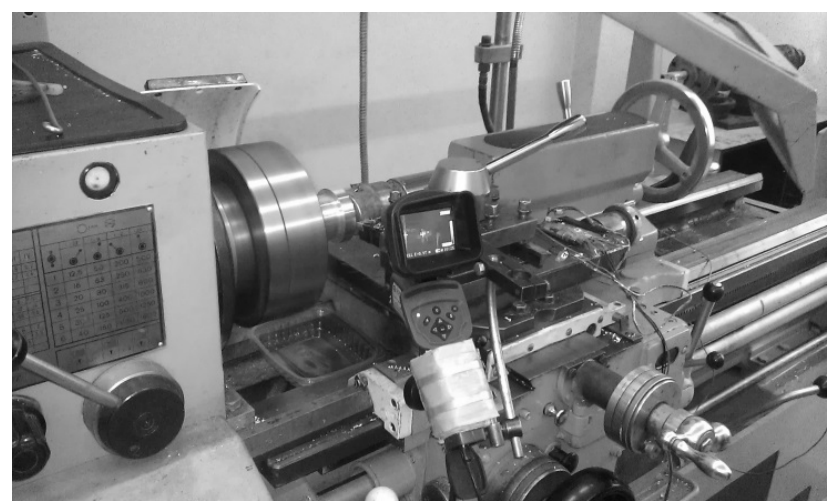

Fig. 1. IR camera installation on the lathe

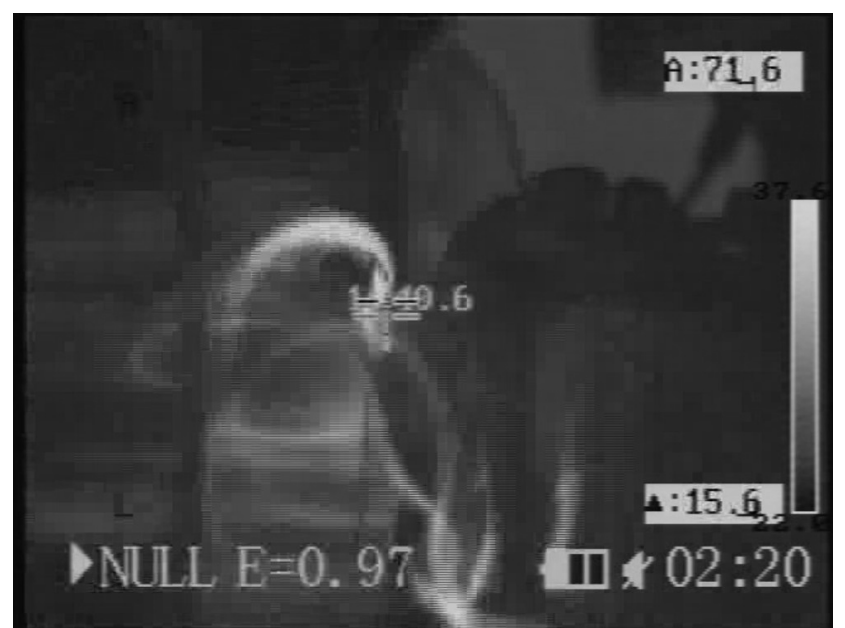

Fig. 2. The thermal spectrum of cutting zone during aluminum alloy D16 turning by hard alloy T15K6 GOST 3882-74 Ti-N coated tool at $\mathrm{v}=50 \mathrm{~m} / \mathrm{min}, \mathrm{S}=0,15 \mathrm{~mm} / \mathrm{rev}, \mathrm{t}=0,5 \mathrm{~mm}$

\section{Conclusion}

Research of surface quality has shown that by increasing the cutting speed the surface roughness reduces. The machined surface roughness increases by increasing the feed. The coated tool provided a better surface quality at high feed. When changing the cutting depth within the range of $0.5-2 \mathrm{~mm}$ the roughness does not change significantly.

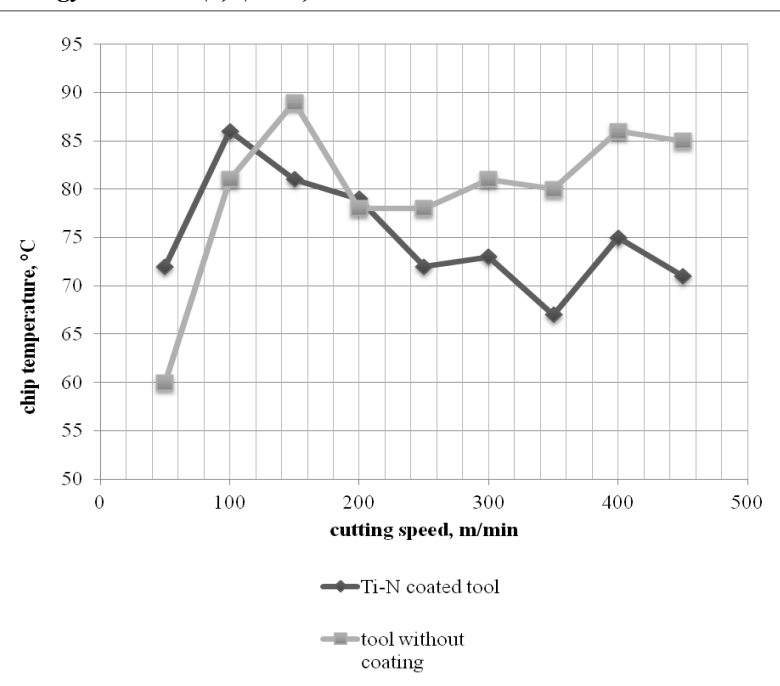

Fig. 3. Effect of cutting speed on chip temperature during aluminum alloy D16 turning with a hard alloy T15K6 GOST 3882-74 tool

Chip temperature graphs for various cutting speeds were obtained during machining by T15K6 coated inserts and by the same tool without coating. Chip temperature in the graphs in the range from 50 to $150 \mathrm{~m} / \mathrm{min}$ increases, and then it decreases with speed increases. The minimum temperature of the chip is observed in the speed range from 300 to $350 \mathrm{~m} / \mathrm{min}$, which corresponds to the area of optimal cutting speeds by A. D. Makarov's definition [2]. The chip temperature during machining by the coated tool is significantly lower (about 10-15\%) than that without coating. It means that the machining by coated tool produces less heat and provides less heat loading to the system. The maximum chip temperature in the researched range of speeds from 50 to $450 \mathrm{~m} / \mathrm{min}$ does not exceed $90^{\circ} \mathrm{C}$.

Thus, machining parameters have a significant impact on the quality of manufacturing details from aluminum alloys. Coated tools allows for improved productivity, surface quality and extended tool life. The obtained mathematical models and experiments allow the simplification of cutting modes and tool selection.

\section{Acknowledgment}

This work was produced during the joint project between USATU (Ufa State Aviation Technical University) and UMPO (Ufa Engine Industrial Association) with title "Elaboration and industrial development of high-precision shaping coordinated technologies and superficial hardening of responsible details from Al-alloys with heightened constructional energy efficiency", implemented under the contract №40/10-30976 sponsored by the Ministry of Education and Science of the Russian Federation (contract №02.G25.31.0010 between UMPO and the Ministry of Education and Science of the Russian Federation) through the Resolution of the Russian Federation Government № 218 from April 9, 2010.
[1] Postnov V. V., Khadiullin S. Kh., Karimov, I. G. Influence of tool microhardness on its wear, Russian Engineering Research, vol. 28, Issue 1, pp. $92-94,2008$ (in Russian).

\section{References}

[2] Khadiullin S. K. Thermodynamic assessment of the operational efficiency of hard-alloy tools, Russian Engineering Research, vol. 9, Issue 12, pp. 1290 - 1292, 2009 (in Russian). 
B. F. Usmanov, S. V. Starovoitov, S. K. Khadiullin and Z. R. Valishina /

Journal of Engineering Science and Technology Review 7 (5) (2014) 51 - 54

[3] Khadiullin S. Kh. Microstructure of worn surfaces of a hard-alloy tool, Russian Engineering Research, vol. 28, Issue 6, pp. $595-$ 597, 2008 (in Russian).

[4] Kishurov V. M., Krioni N. K., Postnov V. V., Chernikov P. P. Materials cutting. Cutting tool, Moscow: "Mashinostroyeniye", 492 p, 2009 (in Russian).

[5] Makarov A. D. Cutting processes optimization, Moscow: "Mashinostroyeniye", 278 p, 1976 (in Russian).

[6] Chernikov P.P., Starovoitov S.V., Sharipov B.U. Influence of the external conditions and the lubricant and coolant fluid on tool-blank contact, Russian Engineering Research, vol. 32, Issue 2, pp. 207 209, 2012 (in Russian).

[7] Makarov A. D., Krivoshey V. M., Nikitin U. V. The application of mathematical experiment planning for the base metal cutting process parameters research, Study guide, Ufa: Publishers of Ufa Aviation Institute named after Ordzhonikidze, 116 p, 1976 (in Russian). 